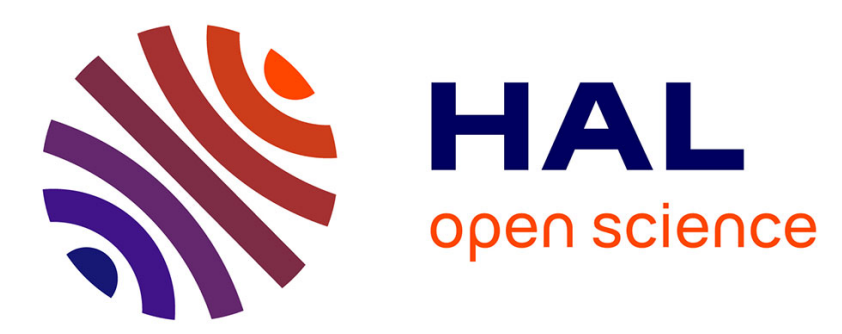

\title{
The influence of bioactive mobile telephony radiation at the level of a plant community - Possible mechanisms and indicators of the effects
}

\author{
Marek Czerwiński, Alain Vian, Amparo Lázaro
}

\section{- To cite this version:}

Marek Czerwiński, Alain Vian, Amparo Lázaro. The influence of bioactive mobile telephony radiation at the level of a plant community - Possible mechanisms and indicators of the effects. Ecological Indicators, 2019, 108, 10.1016/j.ecolind.2019.105683 . hal-02625424

\author{
HAL Id: hal-02625424 \\ https://hal.inrae.fr/hal-02625424
}

Submitted on 26 May 2020

HAL is a multi-disciplinary open access archive for the deposit and dissemination of scientific research documents, whether they are published or not. The documents may come from teaching and research institutions in France or abroad, or from public or private research centers.
L'archive ouverte pluridisciplinaire HAL, est destinée au dépôt et à la diffusion de documents scientifiques de niveau recherche, publiés ou non, émanant des établissements d'enseignement et de recherche français ou étrangers, des laboratoires publics ou privés. 
Review

\title{
The influence of bioactive mobile telephony radiation at the level of a plant community - Possible mechanisms and indicators of the effects
}

\author{
Marek Czerwiński ${ }^{\mathrm{a}, *}$, Łukasz Januszkiewicz ${ }^{\mathrm{b}}$, Alain Vian ${ }^{\mathrm{c}}$, Amparo Lázaro $^{\mathrm{d}}$ \\ ${ }^{a}$ Department of Grassland and Natural Landscape Sciences, Poznań University of Life Sciences, ul. Dojazd 11, 60-632 Poznań, Poland \\ ${ }^{\mathrm{b}}$ Institute of Electronics, Lodz University of Technology, ul. Wólczańska 211/215, 90-924 Łódź, Poland \\ ' IRHS, Université d'Angers, Agrocampus-Ouest, INRA, SFR 4207 QuaSaV, 49071 Beaucouzé, France \\ ${ }^{\mathrm{d}}$ Mediterranean Institute for Advanced Studies, Global Change Research Group, C/Miquel Marquès 21, 07190 Esporles, Balearic Islands, Spain
}

\section{A R T I C L E I N F O}

\section{Keywords:}

Wireless communication

Mobile phone radiation

Ecosystem

Ecological effect

Species diversity

Species interactions

\begin{abstract}
A B S T R A C T
Environmental exposure to radiofrequency electromagnetic fields (RF-EMFs) from mobile telephony has rapidly increased in the last two decades and this trend is expected to continue. The effects of this exposure at plant community level are unknown and difficult to assess in a scientifically appropriate manner. Such an assessment can be scientifically adequate if a studied plant community is completely new and control-impact radiation treatment is used.

In this review we aimed to predict ecological effects and identify indicators of the impact of bioactive RFEMFs at the mobile telephony frequency range on plant communities. We considered the scenario where a plant community was exposed to radiation generated by a base transmitting station antenna mounted on a nearby mast. This plant community can be represented by mesic meadow, ruderal or arable weed community, or other herbaceous, moderately productive vegetation type. We concentrated primarily on radiation effects that can be recorded for a year since the exposure started. To predict them we used physical theories of radiowave propagation in vegetation and the knowledge on plants physiological responses to RF-EMF. Our indicators can be used for the detection of the impact of RF-EMFs on vegetation in a control-impact experiment.

The identified indicators can be classified into the following groups: (1) canopy parameters; (2) plant characteristics to be measured in the field or laboratory in a number of individuals that represent the populations of selected species; (3) community weighted means/medians (CWMs) of plant traits and strategies; (4) the abundance of other organisms that interact with plants and can influence their fitness or population size. The group of canopy parameters includes mean height, vertical vegetation structure and dry weight of above-ground standing phytomass. Plant characteristics requiring biometric sampling in the field are plant height, the number of fruits and seeds, as well as seed viability. The group of plant traits that are calculated as CWMs covers seed releasing height, seed dispersal mode, SLA, leaf orientation, month of germination and flowering, Ellenberg's light indicator value, and the proportion of individuals in the classes of competitors and stress tolerators according to Grime's CSR strategy scheme. The group of "non-plant" indicators includes primarily the frequency of flower visits by beetles, wasps, hoverflies, and bees that have their nests over ground. To detect ecological responses that occur for the first year since a herbaceous community has been exposed to potentially bioactive RF-EMF, the first two indicators groups should be used.
\end{abstract}

\section{Introduction}

The experiments of plant exposure to radiofrequency electromagnetic fields (RF-EMF) have been carried out at least since the 1970s (Tanner and Romero-Sierra, 1974). From 1974 to 2017 over 80 original peer-reviewed studies were published on this topic, and ca. $90 \%$ of them showed significant effects on plants such as the inhibition, or more rarely, stimulation of growth, changes in various metabolic activities and alteration of gene expression (Cucurachi et al., 2013; Senavirathna and Asaeda, 2014; Vian et al., 2016; Halgamuge 2017). In some of these studies (Pesnya and Romanovsky 2013; Halgamuge et al., 2015; Waldmann-Selsam et al., 2016) the exposure did not exceed the

\footnotetext{
* Corresponding author.

E-mail addresses: m.czerwinski@up.poznan.pl (M. Czerwiński), lukasz.januszkiewicz@p.lodz.pl (Ł. Januszkiewicz), alain.vian@univ-angers.fr (A. Vian), amparo.lazaro@imedea.uib-csic.es (A. Lázaro).
} 
levels that occur in the vicinity of mobile phone base stations (Mann et al., 2000; Urbinello et al., 2014; Chief Inspectorate of Environmental Protection of Poland, 2018). This means that the biological effects of RF-EMF observed under artificial, experimental conditions may occur also in the environment, at the scale of plant communities or ecosystems. Moreover, the size of these effects is likely to increase in the future, because the level of environmental exposure to RF-EMFs is expected to rise as a consequence of the increasing demand for mobile devices and services, as well as by the release of new high frequency bands for radiocommunication by governments (European Commission, 2016).

Although the literature on the effects of RF-EMF on plants is extensive, not a single field study has assessed the biological response at the level of a plant community or ecosystem, but nearly all the publications describe short-term laboratory studies conducted on single species. This dissonance is particularly striking in view of the fact that alterations in a plant community's structure and composition have long been considered to be well founded, sensitive and universal environmental indicators (de Boer, 1983; Stohlgren, 2006). This substantial literature gap developed possibly due to the practical difficulty to assess the impact of human-made electromagnetic radiation on an existing, multi-species plant community in a scientifically rigorous way (Smith, 2006). Studying this impact using a Control-Impact Design is problematic, as the patches of species-rich vegetation in the natural electromagnetic environment are already rare. This is because normally the zones with low human population density, and the absence of wireless communication infrastructure are characterized by vegetation of simplified ecological structure due to unfavorable climatic conditions and poor soils. In such conditions, the opportunity for studying plant-plant interactions, such as competition, is limited. One may think that vegetation patches isolated from anthropogenic radiation due to geomorphological conditions, i.e. located in valleys, gorges, canyons, etc., can be used as control but they may be functionally connected with other landscape elements (the surrounding vegetation patches), covered by wireless communication networks. Investigating the impact of EMFs on existing vegetation using a Before-After Design is also complicated, because the response of vegetation might be non-specific, which makes it difficult to distinguish the effect of artificial RF-EMF from the long-term effects caused by other environmental factors, which could have acted before the start of the irradiation. Besides, local environmental conditions may overcome or limit the expression of EMF-induced plant responses. Probably the most feasible way to investigate this impact in a scientifically correct way is to restore or create completely new patches of some specific vegetation type and use an experimental, control-impact radiation treatment. These patches should represent vegetation which is native to the area of study and includes many plant species that differ in terms of morphological or physiological features, to record different potential species-specific responses to RF-EMF. The experiment should be set up in an area where the biological impact of man-made radiation sources is negligible. The size and number of the new vegetation patches should ensure the representativeness of the resulting data. Half of each patch should be irradiated with experimental RF radiation from directional, microwave antennas to simulate the exposure under normal environmental conditions. Radiation effects could be assessed by comparisons of vegetation properties between the irradiated and non-irradiated part. In such a study RFEMF impact can be isolated from other environmental impacts. The recent progress in restoration ecology and ecological engineering enabled ecologists to create species-diverse ecosystems in a relatively short time (Perring et al., 2015; Wainwright et al., 2018). Previous studies have mentioned different experimental ideas for testing RF-EMF effects in ecological communities; Cucurachi et al. (2013) postulated that such research could be carried out after experimental shutting down the communication stations for some period while Malkemper et al. (2018) proposed exposing the populations of wild animals to controlled RF field using coil-collars or coil systems around outdoor enclosures.

In this paper we aim at identifying useful ecological indicators of the effects of the exposure of a plant community to the radiation used by different mobile phone networks in rural or suburban areas. We focus mainly on the frequency range from 0.7 to $1.8 \mathrm{GHz}$, because this range is utilized by cellular technologies that contribute most to the outdoor exposure in rural and suburban areas (Joseph et al., 2012). To achieve this aim, we used theory that is applied in telecommunication engineering and remote sensing to model radiowave propagation in vegetation bodies. We searched for indicators that can be applied for the detection of the impact of EMF on vegetation in a control-impact in natura experiment, but not for environmental monitoring. We hope that this paper will help establish the theoretical basis to design such an experiment. The cited sources of data on plant species traits refer mainly to Central Europe, the region where we have conducted ecological studies. We considered the impact of RF-EMF on moderately productive, multi-species herbaceous community, in which inter-specific competition for light plays a significant role in shaping species composition and the architecture of canopy. By moderate productivity we mean $0.4-0.8 \mathrm{~kg} \mathrm{~m}^{-2}$ of dry matter per year (Leuschner and Ellenberg, 2017) which equals to the production of $1.3-2.6 \mathrm{~kg} \mathrm{~m}^{-2}$ of standing above-ground phytomass, assuming that gravimetric water content of the phytomass is 0.7 (Jefferson, 1999). This community can be represented by vegetation types such as species-rich mesic meadows, arable weed communities or ruderal communities that are composed of graminoids and forbs (Leuschner and Ellenberg, 2017). Herbaceous communities are particularly suitable to assess the radiation effects because:

1. physiognomy of herbaceous communities allows to determine their composition, foliage-canopy structure, and other characteristics relatively quickly and on small observation plots;

2. herbs undergo periodic shoot reduction and live for a relatively short time, which allows to observe their response to radiation from the development of above-ground tissues and organs to seed production;

3. the information on different canopy parameters is readily available for different herbaceous vegetation types; canopy parameters (vertical distribution of leaf area index, leaf area density, biomass density) are useful for analyzing RF-EMF propagation in vegetation;

4. the creation of herbaceous communities is faster and less complicated when compared to woods; also, the knowledge on the creation of semi-natural grasslands is particularly extensive because they are often restored for nature conservation;

5. some herbaceous communities, such as lowland dry meadows, represent a considerable diversity of plant species and traits, with multi-level, intricate relationships.

We focus our analysis on plant community responses that are most likely to occur during the first year of exposure to RF-EMF from base transmitting station (BTS), when new generation of herbaceous plant species passes the stages of vegetative and generative growth, and completes the stage of seed shedding. Note that the effects of mobile telephony radiation which have been noticed in natura in non-cultivated plants, have been reported probably only for trees and not for herbs (Appendix A). This may be because the relatively long life span of trees makes them exposed to radiation for longer periods. The duration of exposure may be as important as radiation power density and energy absorption rate (Belyaev, 2010). Therefore, the experiment suggested here might not detect some long-term effects that could be revealed if it was carried out for several years on woody perennials, such as Calluna vulgaris, or other evergreen chamaephytes. Nevertheless, the analysis for periods longer than one year (one growing season for annuals) is much more complicated because it requires including additional factors, such as plant life span, the position of the vegetative perennating buds during the winter (Raunkiaer's classification of plant life forms), 


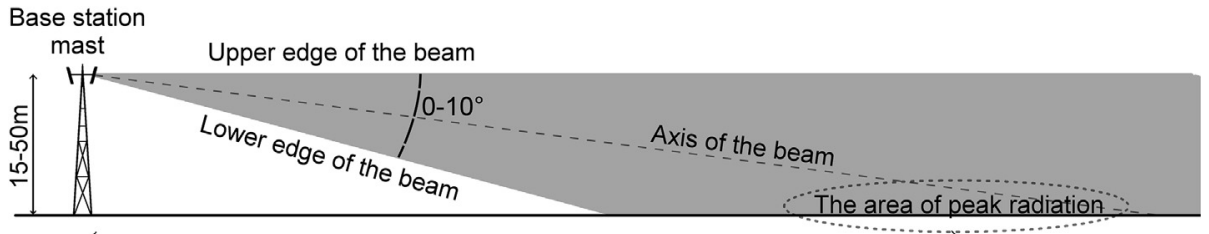

A few dozen - a few hundred meters

mode of reproduction, etc. With so many factors to consider, it is risky to make predictions on ecological responses of a plant community.

In this manuscript we will often refer to the radiation exposure level that is above the response threshold, estimated after a detailed analysis of the relevant literature, for plants or other living organisms that interact with plants in the considered vegetation types. For convenience, we use this descriptive term interchangeably with "biologically active" or "bioactive" radiation level.

\section{Methods}

In order to identify ecological indicators of RF-EMF impact on herbaceous vegetation, we performed an extensive literature review in three different stages in which different literature sources were used. This is reflected in the division of our manuscript into three relevant Sections (3, 4 and 5).

In the first stage (Section 3), we defined exposure conditions and key parameters of bioactive RF-EMF that represent expected real-life irradiation scenarios. We also described expected physiological plant responses to the radiation. Literature on this subject was summarized in Appendix A. In this summary, we excluded papers in which the information on radiation exposure level was not provided or significance of the obtained results was not determined. The defined radiation conditions and the expected specific plant physiological responses provided the framework of our study.

In the second stage (Section 4), we reviewed physical theory that can be applied to determine vertical distribution of RF-EMF in a herbaceous canopy and the absorption of radiation energy by individual plants. We also calculated the attenuation of RF energy that passes through the canopy of a herbaceous community. These calculations, presented in Appendix B, were essential to formulate the conclusions from our study.

In the third stage (Section 5), we used the described physical phenomena and introduced physical laws to predict ecological responses in a herbaceous community to RF-EMF. Based on these predictions, we proposed ecological indicators of RF-EMF impact.

The papers for our review were selected using Google Scholar, EMFPortal (www.emf-portal.org) and Web of Science Core Collection. We considered only peer-reviewed studies, which were published in journals indexed in the Web of Science database.

\section{Theory that underpins our study and provided basis for our predictions of radiation effects in plant communities}

Our study is based on specific assumptions regarding conditions of the RF-EMF exposure. We consider these conditions as representative of real-life scenarios. We also expect specific plant physiological responses to the radiation. The following theory provides the framework of our study:

1. Potential effects of man-made RF-EMFs on vegetation are most likely to occur in the areas surrounding mobile phone base stations.

The measurements of RF-EMFs carried out in different developed countries show that power flux density in outdoor suburban and rural areas typically does not exceed $10^{-3} \mathrm{~W} \mathrm{~m}^{-2}$, and the highest values are recorded near mobile phone base stations (Mann et al., 2000; Henderson and Bangay, 2006; Kim and Park, 2010; Urbinello et al.,
Fig. 1. Schematic diagram showing the shape of the beam formed by a typical directional antenna used with a macrocellular base station.
2014; Chief Inspectorate of Environmental Protection of Poland, 2018). This means that the effects of man-made RF-EMFs on vegetation, if any, should probably be sought first in places of peak radiation around cellular base stations.

2. Electromagnetic waves that most likely influence species interactions in a plant community, come from one dominant direction and fall at angle of $3-10^{\circ}$ to the ground surface

Transmitters which are utilized in a BTS usually comprise directional antennas that generate a cone-like beam of main radiation (that is wider in horizontal plane than in vertical). The lateral and vertical dimensions of the beam are defined in terms of their half power beam width, i.e. the angle between the points where power is reduced by $50 \%$ $(3 \mathrm{~dB})$. The beam is tilted slightly downwards so the top edge of the main beam is approximately horizontal, whereas the lower edge is directed up to $10^{\circ}$ below horizontal. On the ground, the highest radiation level tend to occur between the point of incidence of the beam axis and the point of incidence of the lower edge of the main beam in the vertical plane (based on a $3 \mathrm{~dB}$ reduction of power) (Briggs et al., 2012). Over this distance, the emitted electromagnetic waves arrive at angle ranging from $3^{\circ}$ to $10^{\circ}$ (Fig. 1). When considering the heights at which antennas are mounted (15-50 m), this implies that the area of peak power flux density can be found a few dozen up to a few hundred meters from the foot of the mast on which antennas are installed (Appendix C). In this area, the electromagnetic signal from the local base station dominates the strength of radiofrequency signals measured, and signals from other environmental radio sources have little additional effect (Mann et al., 2000).

3. The minimum bioactive exposure level (peak values of the pulsed signal) for plants can be expected typically within the range of $10^{-4}-10^{-2} \mathrm{Wm}^{-2}$

In order to determine the exposure level which is the threshold of response in plants, we conducted a detailed survey of literature where significant effects of RF-EMF were observed in plants at non-thermal exposure levels (see Appendix A). This literature indicates that the exposure level (time-averaged value) which is the threshold of response in plants can be expected typically within the range of $10^{-4}-10^{-2} \mathrm{~W} \mathrm{~m}^{-2}$. This level may depend on the mean power level, carrier frequency, and the low frequency amplitude modulation of the electromagnetic signal (Halgamuge et al., 2015). The relationship between power flux density in the non-thermal range and the magnitude of effect is difficult to identify and is probably non-linear. In most studies the intensity of plants reaction increased with the increasing power density (Halgamuge et al., 2015; Waldmann-Selsam et al., 2016). Similar response regardless of the exposure level was observed by Roux et al. (2006). The assumed threshold value is based on limited evidence and mainly on short-term studies, so it should be regarded as tentative until more empirical data is collected.

4. Polarization of electromagnetic waves, that is typical for RF-EMF generated from cellular antennas, may increase its bioactivity

In wireless mobile communication systems, electromagnetic waves with linear polarization are often utilized. This polarization is often vertical because vertical antenna polarization has been the standard configuration for cellular BTSs for many years. In modern wireless systems, two orthogonal linear polarization are often used (Weitzen and Wallace, 2002). In radiowave propagation scenario considered in this paper there are no physical obstacles between the BTS and vegetation 

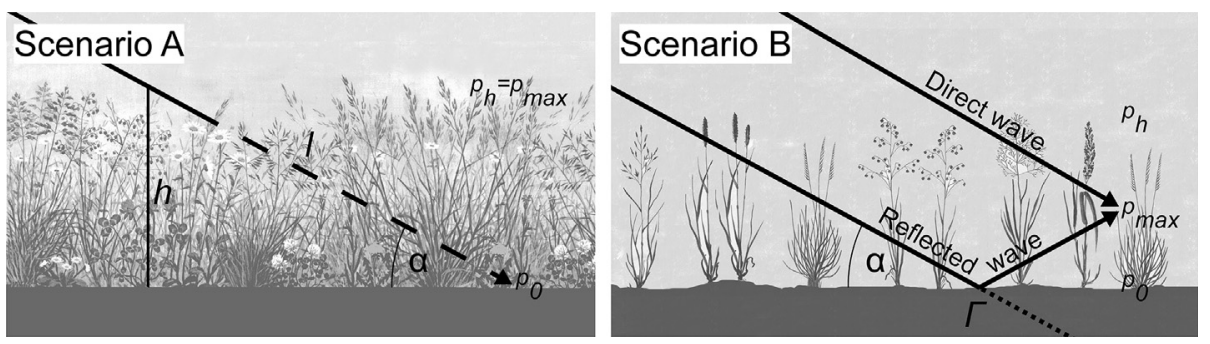

Fig. 2. The propagation of bioactive RF-EMF in the canopy of herbaceous vegetation; in scenario A the canopy is dense so that the radiation is attenuated to the level which does not elicit physiological response in plants; in this scenario, EMF power density is the highest above the canopy; in scenario B bioactive radiation penetrates the entire canopy profile and is reflected off or absorbed by the ground; in this scenario, EMF power density is the highest within the canopy; symbols used: $h$ - mean canopy height; $\alpha$ - radiation incidence angle; $l$ radiation path length $\left(l=h / \sin \alpha\right.$; for $h=1 \mathrm{~m}$ and $\left.\alpha=3^{\circ}, l=19.1 \mathrm{~m}\right) ; p_{0}$ - power density of the incident radiation at the ground level; $p_{h}-$ power density of the incident radiation at height $h ; p_{\max }$ - maximum power density in the canopy; $\Gamma$ - ground reflection coefficient.

canopy (there is no wave diffraction nor reflection that could alter wave polarization on wave propagation path). Therefore it can be assumed that radiowaves that fall upon the vegetation canopy are also linearly polarized.

It has been hypothesized that polarized RF-EMF have the ability to disrupt the cell's electrochemical balance (Panagopoulos et al., 2015a). Wave polarization and field power density are two parameters that deserve special attention in our study, because these parameters change as radio wave penetrate vegetation canopy (see Section 3).

5. The ultimate physiological effects of long-term exposure of plants to $R F-E M F$ are adverse and lead to the deterioration of plant condition as well as to the inhibition of growth and development

Although RF-EMF can both stimulate and inhibit plant germination, development or growth, an inhibitive impact was observed in the overwhelming majority of the studies (Appendix A). Different hypotheses have been developed to explain the mechanisms that underlie this impact (see Appendix D for the review of these hypotheses), but further research is needed in this area. Nevertheless, physiological responses in plants are similar to those triggered by injurious stimulation or environmental stressful conditions, such as drought, heat, cold, high salinity, soil mineral deficiency and toxicity (e.g. Beaubois et al., 2007; Sharma et al., 2009; Singh et al., 2012; Soran et al., 2014). Plant responses were observed not only in the tissues directly exposed but also in distant organs (Beaubois et al., 2007). Some researchers postulate that the stress response of plant and animal cells should be an appropriate biological guideline to evaluate electromagnetic safety and the effects of long term and complex repeated exposures (Blank and Goodman, 2004; Panagopoulos et al., 2015b).

\section{Radiofrequency radiation exposure of plants in a herbaceous canopy in the language of physics}

\subsection{Vertical distribution of potentially bioactive electromagnetic field in a herbaceous canopy}

Biologically active radiofrequency radiation can have various effects on a herbaceous community, depending on its intensity in the vegetation canopy. Therefore, it is important to determine vertical distribution of EMF energy in the canopy. In the assumed propagation scenario (Section 2), this distribution is determined mainly by frequency and power density of the radiation falling upon the canopy, the inclination of radiation beam axis, reflection from the ground surface as well as by the properties of the irradiated vegetation canopy. The properties of canopy considered here are its height and the coefficient of wave attenuation (or extinction) in vegetation, $\gamma\left(\mathrm{dB} \mathrm{m}^{-1}\right)$ (Goldhirsh and Vogel, 1998; Chukhlantsev, 2006). The value of $\gamma$ depends on the absorption and scattering of radiation in a vegetation medium (Goldhirsh and Vogel, 1998; Chukhlantsev, 2006). It can be calculated using Eq. (1) (Chukhlantsev, 2006):

$\gamma=\rho \times m_{v} \times b$

where: $\rho$ - vegetation volume density, i.e. average vegetation mass in the canopy per unit volume $\left(\mathrm{kg} \mathrm{m}^{-3}\right)$;

$m_{v}$ - volumetric moisture content of plants (-);

$b$ - proportionality coefficient $\left(\mathrm{dB} \mathrm{kg}^{-1} \mathrm{~m}^{2}\right)$.

Empirical studies showed that at decimeter wavelengths (frequency $1-2 \mathrm{GHz}$ ) the value of $b$ is similar for alfalfa, rye, wheat, pea, pasture grasses and other common agricultural crops that represent different plant architectures (broad-leaved forbs vs. narrow-leaved graminoids) (Chukhlantsev, 2006; Appendix B). This indicates that the value of $b$ determined for crop plants can be used also for different types of multispecies herbaceous vegetation, including grasslands as well as ruderal and arable weed communities.

Theoretical calculations and field measurements carried out for the frequency range from 1 to $2 \mathrm{GHz}$ show that the attenuation coefficient ranges from 1.0 to $2.0 \mathrm{~dB} \mathrm{~m}^{-1}$ for the considered herbaceous communities (Chukhlantsev, 2006; Mestre et al., 2010; Olasupo et al., 2016; Appendix B). This means that for slant-path propagation in which the EM wave propagates in canopy on much larger distances than its height, high and dense herbaceous canopies attenuate radiation power density by one or two orders of magnitude before the electromagnetic waves reach the ground surface. This in turn suggests that the exposure of plants to biologically active radiation can occur mainly in the upper and middle parts of herbaceous vegetation profile, whereas the exposure levels near the ground are below plants' response threshold to radiation (Fig. 2, Scenario A). It should be noted, however, that systemic responses routinely occur in plants after local (i.e. partial) stimulation, including exposure to RF-EMF (Beaubois et al., 2007). Consequently, a direct exposure of plant tissue may not be required to achieve biological responses.

Attenuation of microwave radiation in vegetation to the levels below plants' response threshold was observed by Waldmann-Selsam et al. (2016). The authors recorded unilateral damages of tree crowns for approximately 700 deciduous and coniferous trees exposed to radiation from phone masts. On the side facing a phone mast, crowns were characterized by sparse foliage, premature color change of leaves, dead branches and other damages, while on the opposite side of the crowns, these damages were not observed. It can be expected that the radiation from a BTS that passes through high herbaceous canopy is attenuated to a similar degree as in tree crowns. This is because the attenuation coefficients for the crowns of tree species studied by Waldmann-Selsam et al. (2016) are similar to those in herbaceous canopies (they range from 0.7 to $2.0 \mathrm{~dB} \mathrm{~m}^{-1}$ at the frequency of $870 \mathrm{MHz}$, Goldhirsh and Vogel, 1998). Also the diameters of tree crowns are similar to the lengths of radio paths in herbaceous canopies (Fig. 2, Scenario A; Appendix B).

It should be emphasized that attenuation of RF-EMF in vegetation to the levels below plants' response threshold can occur only if the canopy is high and dense, and the constituent plants are still growing (so that water content in plant tissues remains high). As suggested by our calculations (Appendix B), bioactive radiation from a BTS penetrates the entire canopy down to the ground surface if vegetation is sparse or low (spring) or if plant hydric status is lowered (which occurs in autumn, 
when plants have entered into the phase of senescence). Radiowaves that pass through herbaceous canopy are partially absorbed in the upper layer of soil and also partially reflected off its surface. In such case, direct and reflected wave interfere with each other. Depending on their phases they can add their energy (when there is no phase difference) or decrease their energy (where there is $180^{\circ}$ phase shift between them). Reflection coefficient $\Gamma$ (the ratio of reflected wave amplitude to the incident wave) for typical ground is 0.6 , so the reflected wave has significantly lower amplitude than the direct wave. Direct and reflected waves that add their energy are expected to increase the total power density near the ground by a factor up to four (but for typical grounds it does not exceed 3.0) (Mann et al., 2000; European Committee for Electrotechnical Standardization, 2017). In such circumstances, maximum EMF power density $\left(p_{\max }\right)$ can occur in the middle, not upper vegetation layer (Fig. 2, Scenario B). For such a scenario, vertical distribution of power density in the canopy can be estimated using a simplified two-ray model. In this model, the electromagnetic field in each point above the reflecting surface is computed with a direct and reflected wave that are added with respect to their phases (PérezFontán and Mariño Espiñeira, 2008). The height in the canopy, where the combination of these two waves gives rise to an interference pattern with the maximum amplitude, is not constant. It increases with increasing wave length and incident angle $\alpha$. This height, as well as vertical distribution of EMF energy in general, might also depend on the value of $\Gamma$ and $\rho$, the latter being usually varied in the canopy profile. It should be stressed that the amplitude of the reflected wave in the considered case can be considerably reduced compared to the energy of the direct wave. This reduction is the effect of the attenuation by vegetation canopy along the path from its top to the bottom ( $l$ in Fig. 2) and the reflection off the ground.

For both scenarios, the radio energy that reaches ground is relatively small. This suggests that biological effects of radiation absorbed in the soil are also small and probably insignificant, but this hypothesis is worth exploring in a specifically designed research.

\subsection{Physical plant species characteristics that influence the absorption of radiofrequency energy by individual plants}

It is generally accepted that biological effects observed in a plant that is exposed to RF-EMF depend on the power absorbed by the plant during the exposure (Vian et al., 2016). This power is determined using the specific absorption rate (SAR), which is an EMF exposure metric for living tissues (Vian et al., 2016). A key factor that determines SAR for plants is the water content of their tissues (Vian et al., 2016; Waldmann-Selsam et al., 2016). Water content of plants has a dramatic impact on their dielectric properties, which are, by definition, a measure of the polarizability of a material when subjected to an electric field (Trabelsi and Nelson, 2003). Another factor that can greatly influence SAR for plants is their architecture (Vian et al., 2007, 2016), particularly in a community that is irradiated from one dominant direction and the distribution of the radiation energy is not uniform in the community profile (the scenario analyzed here). Based on the theory of radiowave propagation in vegetation (Chukhlantsev, 2006), SAR might be higher for plants that have relatively large total surface area of leaves and arrange their leaf blades perpendicular, rather than parallel, to the radiation beam axis. Also, SAR is likely to be higher for plants that have their foliage located higher than their neighbors.
5. Radiofrequency radiation exposure of plants in a herbaceous canopy in the language of ecology

\subsection{Plant species' traits that are most likely to be affected by RF-EMF exposure}

\subsubsection{Common traitbases as a reference for the identification of ecological indicators}

Making predictions on the structure, dominance and diversity of a plant community from plant-level responses is very difficult because plant communities create complex and dynamic systems. To make such predictions easier, ecologists use a functional approach, which consists in reducing the number of species investigated by grouping them into 'functional groups'. Functional groups are distinguished by 'functional traits' of species, i.e. traits which are considered relevant to the response of those species to the environment and/or their effects on ecosystem properties (Violle et al., 2007). The use of functional approach in ecology was largely facilitated by the compilation of species functional traits in databases, such as LEDA, BIOLFLOR, TRY etc. (Klotz et al., 2002; Kleyer et al., 2008; Kattge et al., 2011). Thus, the functional characteristics of a plant community can be often derived from species composition only, without measuring traits of those species in the field. The development of traitbases was associated with the publication of handbooks with protocols for standardized measurements of plant traits (e.g. Pérez-Harguindeguy et al., 2013). We used these traitbases and protocols as a reference to propose ecological indicators from plant biophysical parameters that can influence absorption of radiofrequency radiation (Section 3 ).

\subsubsection{Height at which foliage is developed}

If the radiation that illuminates a herbaceous community is attenuated to non-bioactive levels before it reaches the soil surface (Fig. 2, Scenario A), the propagating energy is expected to be absorbed mostly by species that develop high canopy or large tussocks, because these species are not shielded by other plants. Also, tall-statured species are likely to respond to the radiation in a different way than their smaller neighbors because of different microhabitat conditions. In the bottom layer of herbaceous canopies light intensity is greatly reduced, and air humidity can be considerably increased. In the middle layer, air temperature is the highest (Fliervoet and Werger, 1984). Plant height can be easily measured in the field, in the number of individuals that represent the populations of selected species within a plot (PérezHarguindeguy et al., 2013). The information on species canopy height has also been collected in traitbases and it is available for most plant species occurring in the temperate zone (Kleyer et al., 2008; Kattge et al., 2011). Plant canopy height is positively associated with plant's ability to compete for light and the capacity for carbon gain (Anten, 2005). However, the fractional allocation of biomass to leaves (another trait which can influence plants response to EMF) generally decreases with height, because height growth involves investments of biomass in support structures (stems, branches and petioles) to maintain mechanical stability (Anten, 2005).

\subsubsection{Seed releasing height, seed dispersal mode and seed viability}

Relative differences in stature between plant species in a multispecies grassland canopy, and the related absorption of biologically active electromagnetic radiation depend also on the height at which inflorescences and fruiting heads are elevated. This characteristic seems particularly important in the context of the exposure of seeds to RFEMF, because it can modify the rate and time of their germination (Scialabba and Tamburello, 2002; Jinapang et al., 2010; Pietruszewski, 2011). In many species, seeds contain a very dehydrated embryo which incubates the reserves (exalbuminated seeds). In the other seeds, the reserves remain outside the embryo in specialized tissues (endosperm or perisperm) whose cells are often no longer alive when they are mature. Most of them also have solid integuments that limit oxygen 
availability in the seed, which inhibits metabolism. It is thus possible that their particular constitution (very low water content, low oxygen tension) makes these organs insensitive to EMF exposure as long as the imbibition has not occurred. The situation is different in fruits, particularly in fleshy fruits or immature dry fruits where the high water content may facilitate interaction with EMF (Kundu and Gupta, 2014; Kundu et al., 2016). It could be hypothesized that an interaction between electromagnetic fields and fruit would have a negative impact on future seed germination. We are currently unaware of any work that raises this question, but the importance of seeds in the population dynamics of many communities makes this a point that should be the focus of future investigations.

The height at which fruits are developed in plants is greatly determined by seed dispersal mode. Relatively high elevated fruits are typical of plants that disperse their seeds by wind (anemochoric plants). For the other seed dispersal modes (hydro, endozoo-, epizoochory), the elevation of fruits is of lesser importance (van der Pijl, 1982). Seed germination rate and time can be tested in a laboratory (Baskin and Baskin, 2014). The height at which fruits are developed and the potential for wind dispersal can be found in traitbases for most herbs in Europe. In LEDA traitbase seed releasing height for plant species is given (Kleyer et al., 2008) and in the $\mathrm{D}^{3}$ traitbase anemochory ranking index is specified (Hintze et al., 2013).

Increased irradiation of flowers in plants growing in a herbaceous vegetation raises questions about RF-EMF effects on the viability of pollen (plant microgametophyte). Pollen is a very small structure (2-3 celled) that has haploid genome, which makes it especially sensitive to gene alteration. Some experiments show that pollen germination was affected by EMF, but they were conducted for low frequencies (Dattilo et al., 2005; Betti et al., 2011; Majd et al., 2013). Further research is required to determine if pollen formation (meiosis of mother cells, tetrad set-up, cell wall acquisition) or functioning (elaboration of pollen tube, delivering of sperm cells to the female gametophyte) can be affected by RF-EMFs.

\subsubsection{Leaf area and leaf water content}

Total surface area of leaves is not widely used in between-species comparisons because it is very time-consuming to determine this parameter for many plant species (Norman and Campbell, 1991). The associated, much more popular species attributes are mean area of a leaf (LA; LA $\times$ no. of leaves $=$ total surface area of leaves) (Kleyer et al., 2008), leaf area per shoot biomass (LAR), and leaf mass as a fraction of total mass (LMF) (Wright et al., 2004; Pickup et al., 2005; PérezHarguindeguy et al., 2013). Data on species leaf water content is not typically included in traitbases, but it can be easily derived from the information on the content of leaf dry matter (LDMC), the complementary component of a fresh leaf. LDMC is a standard trait in ecological databases (Kleyer et al., 2008; Kattge et al., 2011). The ratio of LA and LDMC yields specific leaf area index (SLA), a characteristic which is considered a principal functional trait of plants (Westoby, 1998). Specific leaf area might be a sensitive indicator in studying the response of plant species to RF-EMF due to the direct dependence on LA and LDMC.

\subsubsection{Orientation of leaves}

Plants that have vertically inclined leaves are more exposed to the radiation than individuals with horizontally oriented leaves when the incident wave is nearly horizontal. Leaf orientation, which remains constant through the leaf life span, is considered a species-specific trait, and it has been already determined for a few thousand taxa (Kattge et al., 2011). Horizontal or shallow angled leaves allow for greater light interception and potentially greater carbon gain, but they also increase self-shading of individuals, genets or ramets within a species. Therefore, horizontal leaves are common in non-clonal species and the "guerrilla" clonal species, which extensively spread their stolons or rhizomes. Vertical leaves are typical of clonal plants whose ramets are closely spaced and shade one another ("phalanx" growth form, typical of tussock species). In those plants light can be utilized by leaves at lower layers, because it passes between the upper leaves. This way, photosynthetic capacity and carbon gain of the whole clone are maximized (Hikosaka and Hirose, 1997; Anten, 2005).

\subsubsection{Time of germination and growth}

The absorption of radiofrequency energy and its biological effects may be particularly significant for plant species that develop their foliage early in the growing season, earlier than the neighbors in a multispecies plant community. Plants that germinate and emerge later may be protected from bioactive EMF because they are shielded by their neighbors. The irradiation effects for early-season plants may be important not only because they grow in a sparse canopy created by dead or still dormant shoots of the other species, but also because the irradiated young tissues leaves undergo the phase of fast growth and contain relatively much water. Serious radiation damages in juvenile plants, exposed to weak EMF, were described by Stefi et al. (2016, 2017a,b,c). The exposure of a juvenile plant to bioactive EMF can affect fitness of this plant in the long term. Grémiaux et al. (2016) showed that axillary buds of Rosa hybrida, that were exposed to extremely low intensity RF-EMFs, produce shoots that grow slower than shoots produced by non-irradiated plants. This effect was observed a few weeks after the exposure had ended.

\subsection{Stage of vegetation growth as an important criterion in selecting the indicators}

The effects of each of the above-mentioned traits on the absorption of RF energy by plants change over time. In spring, when the considered plant community is young, sparse and low, electromagnetic waves may penetrate entire vegetation profile and reach the surface layer of soil (see Section 3). At this time, probably the most important factor that determines energy absorption by individual species is month of their germination, seedling emergence and development of above-ground organs. Other traits, important at this early stage of community development, are water content in plants, as well as the area and orientation of leaves.

At the end of spring, thick and dense canopy of plants is developed, and, as a result, the intensity of inter-specific competition for light increases. In these conditions most of the bioactive radiation is likely to be absorbed or scattered in the upper part of the vegetation profile. Therefore, at this time, the absorption of RF energy by individual plant species greatly depends on the characteristics which determine plant's success in the competition for light, particularly on canopy height.

\subsection{Plant-plant interactions}

There are different forms of plant-plant relationships in mesic grasslands: competition, allelopathy, parasitism, facilitation and mutualism. Among these interactions, competition has always been foremost in the understanding of community structure in herbaceous communities (Gibson, 2009; Grime, 1979). Competitive relations drive differentiation of canopy height, SLA, leaf inclination, and other species traits within a community. They are also commonly considered to determine plant community composition, productivity, dynamics, and diversity in grasslands (Grime, 1979; Briske, 2007). Competition, which may revolve around different environmental resources: water, light, and nutrients, occurs between individuals of different species (interspecific competition) and between individuals of the same species (intraspecific competition). In multispecies herbaceous communities, the exclusion of plant species is most often caused by the competition for light (Hautier et al., 2009), which is associated with the directionality of light supply. Due to this directionality, faster growing or taller species can preempt this resource and shade those beneath. A small advantage in height therefore allows much more of the light to be 
intercepted, conferring a disproportionately large competitive advantage. This mode of competition, which is disproportionate to some measure of size, is called 'size-asymmetric' (Vojtech et al., 2007). In contrast, the competition for water and nutrients is often assumed to be size-symmetric, because these resources are supplied omnidirectionally.

The reduction of the fitness of fast growing and tall-statured species under radiowave exposure is expected to cause the decrease in the asymmetry in the competition for light. Theoretically, this should lead to the overall slowdown of the growth of plants and the reduction of relative differences in size between them (Vojtech et al., 2007). We note, however, that these hypothetical effects may prove to have limited significance due to the fact that species of the greatest ability to compete for light, project their leaves horizontally to monopolize this resource, which reduces RF-EMF effects.

Plants can communicate through volatile organic compounds (VOCs) that act both as allelochemicals and as neighbour detection signals (Kegge and Pierik, 2010). The emission of VOCs was recently found to be evoked by EMF exposure (Soran et al., 2014; Lung et al., 2016) but the effects at plant community level have not been evaluated yet. Moreover, there may be functional link between EMF-stimulated VOCs emission and several plant-insect interactions, such as pollination or pathogenicity (see Section 4.6), because VOCs are signal-molecules for these interactions (Heil, 2014).

One might also hypothesize that RF-EMF increases the role of facilitation in structuring plant communities. It is easy to explain it for the scenario in which radiation power density is the highest in the upper layer of the vegetation exposed to bioactive RF-EMF (Fig. 2, Scenario A). In these exposure conditions large or tall-statured species facilitate growth of their smaller neighbors by shielding them from the radiation. Predicting changes of the other forms of plant-plant relationships runs a high risk of drawing erroneous inferences because these relationships are poorly known and their role can be very different across the types of herbaceous vegetation. It is also difficult to identify universal indicators of such effects. The comparison of metabolic profiles between directly exposed plants and their neighbors, more or less protected (masked) could constitute a first method to answer these questions. Indeed, these techniques have progressed significantly in recent years and they are competitive alternatives to more traditional approaches (Arbona et al., 2013). In addition, precise information provided by these analyses makes it possible to search for morphological markers in adequacy with these modifications (i.e. height of plants and diameter of their stems if lignification is increased).

\subsection{Plant ecological strategies}

Ecological response of a herbaceous community to RF-EMF can be better predicted if considered in relation to plant strategies, i.e. the manners in which species secure carbon profit during vegetative growth and ensure gene transmission into the future (Westoby et al., 2002). Strategies represent multiple functional traits, which are correlated due to evolutionary or biophysical constraints and trade-offs (Reich et al., 2003). When vegetation descriptions are condensed into strategy categories rather than listing each species individually, ecologically important information is retained and instructive patterns and contrasts between communities emerge.

Among many ecological strategy schemes (or models) proposed (see review in Westoby, 1998), the CSR model developed by Grime (1979) is the most widely used now. In Grime's model, three different plant life histories represent a continuum of adaptations and trade-offs to interspecific competition (C), environmental stress (S), or disturbance (R) for ruderals. Competitors are species that are able to maximize relative growth rate $\left(\mathrm{RGR}_{\max }\right)$, and rapidly make use of abundant above- and below-ground resources. Stress tolerant species are distinguished by low $\mathrm{RGR}_{\max }$ and the ability to withstand low resource levels and low disturbance. Ruderals are species that can exploit newly created, lowstress, highly or frequently disturbed habitats. The impact of artificial
$\mathrm{RF}$ radiation, if analyzed from the perspective of Grime's scheme, would be the most negative for competitors, whereas stress-tolerant species would be the least affected. The information on strategy according to Grime for plant species occurring in Europe has been collected in Biolflor traitbase (Klotz et al., 2002).

Another strategy scheme, which is potentially useful for this analysis, is based on species tolerance for shade (realized light niche), expressed in so-called 'light indicator value'. In Central Europe, the most extensively used classification of species with respect to light was created by Ellenberg and Leuschner (2010), who ordered species from those that have their peak occurrence in shaded habitats (low indicator values) to those that typically occur in sparse canopies or develop higher canopy than the neighbors (high indicator values). It may be hypothesized that species with highest indicator value for light are also the most affected by biologically active, man-made RF radiation. However, species with high L-numbers may have also hardy leaves, indicated by low SLA and low LAR, which may reduce the absorption of RF-EMF.

One more scheme of plant strategies, which is relevant to our study, was created by Westoby (1998). In this model the strategy is determined by three traits: canopy height, SLA and seed mass. In our study, canopy height and SLA were also identified as potentially important for the absorption of RF radiation (Section 4). The key role of these traits in distinguishing different strategies of plants confirms that man-made RF-EMF, if biologically active, influences not only selected species, but also general community-level processes.

\subsection{Mean height and vertical structure of vegetation canopy}

It is possible that RF-EMF can influence not only morphology of individual plants and interactions between them, but also the physiognomy of plant community composed by those plants. This is particularly likely when this community physiognomy is shaped by plants affected by the radiation or when the intensity of competition is decreased under RF-EMF exposure (see Section 5.3). The physiognomy of plant community is often characterized using mean height, vertical structure of canopy and the dry weight of above-ground standing phytomass. These parameters can be sensitive indicators of RF-EMF bioactivity because they can be determined with precise, convenient and standardized methods (Laca and Lemaire, 2000; Stewart et al., 2001; Zehm et al., 2003).

\subsection{The interactions between plants and other living organisms}

5.6.1. Rationale for the studies on RF-EMF impact on plants mediated by other organisms in herbaceous vegetation

In a herbaceous community, the fitness, reproduction and survival of plants depend on other species groups, such as insects, snails, mammals or fungi. These organisms could also be influenced by RFEMF at environmental radiation levels (see below). This means that RFEMFs could affect plant community properties directly, by affecting the irradiated plants, and indirectly, through the impact on organisms that interact with plants. Although there is not enough empirical evidence yet to evaluate to which extent these indirect effects can modify radiation effects in plants, it is certain that animals and other organisms that interact with plants can play key ecological roles in herbaceous communities. Therefore, in the next sections, we review current knowledge on the effects of radiation on them and shortly describe how these RF-EMF indirect effects could be estimated in the proposed experiment.

\subsubsection{Plant-insect interactions}

Plant-insect interactions are ubiquitous and important for the survival of plants. Several laboratory studies on different insect species have shown negative effects of mobile telephony radiation on their reproductive success (e.g. Panagopoulos and Margaritis, 2010; 
Panagopoulos et al., 2010; Sharma and Kumar, 2010). Radiofrequency EMF may also affect visual and olfactory memory (Cammaerts et al., 2012), and locomotion and orientation (Cammaerts et al., 2014; Cammaerts and Johansson 2014) of insects.

Plant-pollinator interactions are one of the most important plantinsect interactions that can be affected by electromagnetic fields in the environment, because losses in the pollinator community may threaten the sexual reproduction of plants and affect the diversity and composition of plant communities. Studies on honeybees have shown that radiation by mobile phone devices can decrease colony strength and oviposition rate (Sharma and Kumar, 2010), induce worker piping, a behavior associated with swarming (Favre, 2011), and reduce hatching of honeybee queens, although not mating success once succeeded the point of pupal development (Odemer and Odemer, 2019). It has also been reported that under electromagnetic radiation, honeybees may encounter difficulties to return to their hives resulting in a massive loss of workers (Sharma and Kumar, 2010). However, still very little is known about the effect of electromagnetic radiation on other insect pollinators in field conditions. Only one study to our knowledge has evaluated the abundance and diversity of pollinators in wild communities in relation to electromagnetic radiation (Lázaro et al., 2016). This study showed that as radiation levels in the environment augmented, the abundance of several pollinator guilds (beetles, wasps and hoverflies) decreased, whereas the abundance of other groups of insects (underground-nesting wild bees and bee flies) increased. Lázaro et al. (2016) hypothesized that larvae developing aboveground (many beetles, wasps, many hoverflies) might be more vulnerable than those developing underground (underground nesting wild bees), because the former may be exposed to higher radiation levels. Pollinators potentially more tolerant to radiation might fill the vacant niches left by less tolerant species and increase their populations. At any rate, radiationrelated changes in the composition of wild pollinators in natural habitats might have ecological impacts on the maintenance of wild plant diversity, and therefore, more studies are needed to evaluate potential changes in the pollinator community in relation to RF-EMF.

Herbaceous communities are normally diverse and very attractive to pollinators, and therefore, they are usually associated with a diverse community of pollinators belonging to many different functional groups. These communities might be particularly exposed to radiation in comparison to others, such as forest communities, because they are more open and therefore they can be easier penetrated by electromagnetic waves. Based on available information, under a scenario of increased electromagnetic radiation, it would be expectable to detect honeybee losses and the relative loss of beetles, wasps, and hoverflies in wild pollinator communities. The decrease in the frequency of flower visits by these insects that develop aboveground, could result in lower seed production in the plants that are pollinated by them and, in the long term, it could lead to the decrease of the populations of these plant species, particularly if they are not able to self-pollinate. The identity of main pollinators of different focal plant species as well as the potential decrease in the number of flower visits under RF-EMF exposure could be detected by means of hand-netting transects to observe flower visitors (Dafni, 1992). Fruit and seed production could be estimated by marking flowering branches in the blooming peak of the community and counting fruits and seeds produced by them after the pollination period (Dafni, 1992). If species' capability of self-pollinating is not available in literature, it could be evaluated using bagging experiments that prevent insects from contacting the reproductive parts of the flowers (Dafni, 1992).

Even more unknown are the effects of radiation on other plant-insect interactions that might be important for the survival of plants, such as the interactions with insects for seed dispersal, or antagonistic interactions such as herbivory or granivory. However, some studies indicate that electromagnetic radiation could be used for pest management in cultivars, as it can control their populations by disrupting development of these harmful insects. For instance, radio-frequency radiation affects weight, development and survival in the larval stage of tobacco hornworms, Manduca sexta (Schwartz et al., 1985) and causes mortality of the granary weevil, Sitophilus granarius (Ponomaryova et al., 2009). As all these studies were carried out in conditions of much higher radiation levels than those found currently in the environment, it is difficult to predict the response of these antagonists. Monitoring the levels of herbivory in leaves and flowers, as well as seed predation in experimental conditions of radiation in comparison to control communities, and estimating their effect on plant reproductive success, will help to understand whether radiation at lower levels also has a negative impact on the antagonist insects of plants and, in turn, indirectly influence plant performance and reproduction.

\subsubsection{Interactions between plants and vertebrates}

Different groups of vertebrates can interact with plants in a herbaceous community that is exposed to experimental RF-EMF treatment. Among vertebrates that occur in temperate European herbaceous communities and live at least partly aboveground, rodents (Rodentia) and shrews (Soricidae) have particular ecological importance (Hayward and Phillipson, 1979). Rodents, such as a vole (Microtus) or a mouse (Apodemus) can impact herbaceous ecosystems mainly through the consumption of plant biomass and selective grazing on more palatable plant species. Shrews are small predators that have a major effect on invertebrate communities in herbaceous vegetation due to their capacity for high population densities and consumption rates (Churchfield et al., 1991). Rodents are likely to be more exposed than shrews to artificial RF-EMFs because they forage above ground level. Shrews, by contrast, are predominantly foragers at ground level or in subterranean burrows (Churchfield et al., 1991). Experimental studies show that when rodents are excluded from grasslands, aboveground plant biomass increases, litter decomposes slower and graminoids invade plant community over 2-3 year time scales (Howe et al., 2006; Moorhead et al., 2017). In bioelectromagnetic research, small rodents comprise an extensively studied group of vertebrates. Despite this, the findings of RFEMF influence can be described as contradictory and inconclusive if environmental levels of RF radiation are considered (Cucurachi et al., 2013; Malkemper et al., 2018). Negative response of rodents nesting in the area under experimental RF-EMF might be detected by the increase in the abundance of grass species that are most preferred by those rodents. This abundance should be considered in relation to the abundance of other grass species that are less often eaten by rodents but have similar traits that can influence their exposure to RF-EMF (see Section 5).

\subsubsection{Other interactions}

Biotic interactions that occur in the upper layer of grassland vegetation involve not only plant-plant or plant-insect relationships, but also interactions with endosymbiotic bacteria and fungi, arachnids, snails, slugs, as well as with fungal, bacterial, viral, or mycoplasma pathogens (Haggar et al., 1984). The impact of RF-EMF on these organisms remains largely unknown (Cucurachi et al., 2013). The activity of plant pathogens under RF-EMF exposure can be assessed through observations of phenotypic abnormalities in plants, such as leaf spots, leaf blotch, chlorosis etc. Similarly, the activity of slugs or snails can be determined by the size of holes (feeding damages) in leaves or flowers. Other interactions are more difficult to observe.

\section{Conclusions}

In this study, we identified several indicators of the impact of bioactive mobile telephony radiation at the level of a plant community. We considered the scenario where a herbaceous plant community was exposed to radiation generated by a BTS antenna mounted on a nearby mast. The identified indicators can be used for the assessment of the impact of RF-EMF on vegetation in a control-impact experiment, but not for environmental monitoring, as when there is not a controlled 
experimental set up, the effect of radiation can be confounded with the effects of other environmental factors. Since these indicators represent different types of community parameters and they are determined using different methods, it is useful to classify them into the following groups:

(1) canopy parameters;

(2) plant characteristics that need to be measured in the field in a number of individuals that represent the population of a selected species within a plot;

(3) community weighted means/medians (CWMs) of plant traits and strategies which are derived from species composition and abundance recorded within the study plots that represent an investigated plant community (the information on these traits and strategies, determined for individual species, is available in online databases);

(4) the abundance of other organisms that interact with plants and can influence their fitness or population size; in this group, the abundance of insects that pollinate plants is particularly important.

The group of canopy parameters includes mean height, vertical vegetation structure and dry weight of above-ground standing phytomass. Plant characteristics requiring biometric sampling in the field that can be suitable to detect the effects of RF-EMF are plant height, the number of fruits per plants, the number of seeds per fruit or seed head as well as seed viability. The group of plant traits that are calculated as CWMs covers seed releasing height, seed dispersal mode, SLA, leaf orientation, month of germination and flowering, and Ellenberg's indicator value for light. It can also be useful to calculate the proportion of individuals in the classes of competitors and stress tolerators according to the CSR strategy scheme (Grime, 1979). The group of "nonplant" indicators includes the frequency of flower visitations by beetles, wasps, hoverflies, and bees that have their nests over ground, and in some cases, also the abundance of invertebrate herbivores and seed predators.

The first two groups of indicators: canopy parameters and plant characteristics that require biometric sampling in the field can be used to detect ecological responses that occur for the first year since a herbaceous community has been exposed to bioactive RF-EMF. Community weighted means/medians of traits are less sensitive when it comes to the detection of short-term ecological responses to RF-EMF. This is because species composition of plant communities might remain largely unchanged throughout one growing season even if environmental conditions are altered.

\section{Acknowledgements}

Marek Czerwiński wishes to thank Prof. Stanisław Kozłowski, Department of Grassland and Natural Landscape Sciences, Poznan University of Life Sciences, for his advice and inspiring discussions on the topic of this manuscript.

\section{Funding}

Amparo Lázaro was supported by a Ramón y Cajal contract (RYC2015-19034) from the Spanish Ministry of Economy and Competitiveness.

\section{Appendix A. Supplementary data}

Supplementary data to this article can be found online at https:// doi.org/10.1016/j.ecolind.2019.105683.

\section{References}

Anten, N.P.R., 2005. Optimal Photosynthetic characteristics of individual plants in vegetation stands and implications for species coexistence. Ann. Bot. 95, 495-506. https://doi.org/10.1093/aob/mci048.
Arbona, V., Manzi, M., de Ollas, C., Gómez-Cadenas, A., 2013. Metabolomics as a tool to investigate abiotic stress tolerance in plants. Int. J. Mol. Sci. 14 (3), 4885-4911. https://doi.org/10.3390/ijms14034885.

Baskin, Carol C., Baskin, Jerry M., 2014. Chapter 2 - ecologically meaningful germination studies. In: Baskin, C.C., Baskin, J.M. (Eds.), Seeds, second ed. Academic Press, San Diego, pp. 5-35. https://doi.org/10.1016/B978-0-12-416677-6.00002-0.

Beaubois, E., Girard, S., Lallechere, S., Davies, E., Paladian, F., Bonnet, P., Ledoigt, G., Vian, A., 2007. Intercellular communication in plants: evidence for two rapidly transmitted systemic signals generated in response to electromagnetic field stimulation in tomato. Plant Cell Environ. 30, 834-844. https://doi.org/10.1111/j.13653040.2007.01669.x.

Belyaev, I., 2010. Dependence of non-thermal biological effects of microwaves on physical and biological variables: implications for reproducibility and safety standards. Eur. J. Oncol. Library 5, 187-218.

Betti, L., Trebbi, G., Fregola, F., Zurla, M., Mesirca, P., Brizzi, M., Borghini, F., 2011. weak static and extremely low frequency magnetic fields affect in vitro pollen germination. Sci. World J. 11, 875-890. https://doi.org/10.1100/tsw.2011.83.

Blank, M., Goodman, R., 2004. Comment: a biological guide for electromagnetic safety: the stress response. Bioelectromagnetics 25, 642-646. https://doi.org/10.1002/bem. 20061.

Briggs, D., Beale, L., Bennett, J., Toledano, M.B., de Hoogh, K., 2012. A geographical model of radio-frequency power density around mobile phone masts. Sci. Total Environ. 426, 233-243. https://doi.org/10.1016/j.scitotenv.2012.03.066.

Briske, D.D., 2007. Plant interactions. In: Barnes, R.F., Moore, K.J., Nelson, C.J., Collins, M. (Eds.), Forages. The Science of Grassland Agriculture. Blackwell Publishing, Ames, Iowa and Oxford, pp. 105-122.

Cammaerts, M.-C., Johansson, O., 2014. Ants can be used as bioindicators to reveal biological effects of electromagnetic waves from some wireless apparatus. Electromagn. Biol. Med. 33, 282-288. https://doi.org/10.3109/15368378.2013. 817336.

Cammaerts, M.-C., De Doncker, P., Patris, X., Bellens, F., Rachidi, Z., Cammaerts, D., 2012. GSM $900 \mathrm{MHz}$ radiation inhibits ants' association between food sites and encountered cues. Electromagn. Biol. Med. 31, 151-165. https://doi.org/10.3109/ 15368378.2011 .624661$.

Cammaerts, M.-C., Vandenbosch, G.A.E., Volski, V., 2014. Effect of short-term GSM radiation at representative levels in society on a biological model: the ant Myrmica sabuleti. J. Insect Behav. 27, 514-526. https://doi.org/10.1007/s10905-014-9446-4.

Chief Inspectorate of Environmental Protection of Poland, 2018. Results of monitoring of electromagnetic field levels in Poland [WWW Document]. URL http://www.gios.gov. pl/images/dokumenty/pms/monitoring_pol_elektormagnetycznych/wyniki_pomiarow monitoringowych za rok 2018.xlsx.

Chukhlantsev, A.A., 2006. Microwave Radiometry of Vegetation Canopies, 2006 ed. Springer, Dordrecht.

Churchfield, S., Hollier, J., Brown, V.K., 1991. The effects of small mammal predators on grassland invertebrates, investigated by field exclosure experiment. Oikos 60 283-290. https://doi.org/10.2307/3545069.

Cucurachi, S., Tamis, W.L.M., Vijver, M.G., Peijnenburg, W.J.G.M., Bolte, J.F.B., de Snoo, G.R., 2013. A review of the ecological effects of radiofrequency electromagnetic fields (RF-EMF). Environ. Int. 51, 116-140. https://doi.org/10.1016/j.envint.2012.10.009.

Dafni, A., 1992. Pollination ecology. In: Rickwood, D., Hames, B.D. (Eds.), A Practical Approach. Oxford University Press, Oxford, UK.

Dattilo, A.M., Bracchini, L., Loiselle, S.A., Ovidi, E., Tiezzi, A., Rossi, C., 2005. Morphological anomalies in pollen tubes of Actinidia deliciosa (kiwi) exposed to 50 $\mathrm{Hz}$ magnetic field. Bioelectromagnetics 26 (2), 153-156. https://doi.org/10.1002/ bem.20086.

de Boer, T.A., 1983. Vegetation as an indicator of environmental changes. Environ. Monit. Assess. 3, 375-380. https://doi.org/10.1007/BF00396232.

Ellenberg, H., Leuschner, C., 2010. Vegetation Mitteleuropas mit den Alpen, 6th ed. Ulmer, Stuttgart.

European Commission, 2016. 5G for Europe: An Action Plan. https://ec.europa.eu/digital-single-market/en/5g-europe-action-plan.

European Committee for Electrotechnical Standardization, 2017. Determination of RF field strength, power density and SAR in the vicinity of radiocommunication base stations for the purpose of evaluating human exposure (IEC 62232:2017).

Favre, D., 2011. Mobile phone-induced honeybee worker piping. Apidologie 42, 270-279.

Fliervoet, L.M., Werger, M.J.A., 1984. Canopy structure and microclimate of two wet grassland communities. New Phytol. 96, 115-130.

Gibson, D.J., 2009. Grasses and Grassland Ecology, 1st ed. Oxford University Press, New York.

Goldhirsh, J., Vogel, W.J., 1998. Handbook of Propagation Effects for Vehicular and Personal Mobile Satellite Systems. Overview of Experimental and Modeling Results (No. A2A-98- U- 0- 021 (APL) EERL-98- 12A (EERL)). The Johns Hopkins University, Applied Physics Laboratory, and the University of Texas at Austin, Electrical Engineering Research Laboratory.

Grémiaux, A., Girard, S., Guérin, V., Lothier, J., Baluška, F., Davies, E., Bonnet, P., Vian, A., 2016. Low-amplitude, high-frequency electromagnetic field exposure causes delayed and reduced growth in Rosa hybrida. J. Plant Physiol. 190, 44-53. https://doi. org/10.1016/j.jplph.2015.11.004.

Grime, J.P., 1979. Plant Strategies and Vegetation Processes. John Wiley \& Sons, Chichester.

Haggar, R.J., Clements, R.O., Carr, A.K.H., Peel, S., 1984. Crop Protection Handbook Grass and Clover Swards. The Lavenham Press Ltd., Lavenham, Suffolk, UK.

Halgamuge, M.N., 2017. Review: weak radiofrequency radiation exposure from mobile phone radiation on plants. Electromagn. Biol. Med. 36, 213-235. https://doi.org/10. 1080/15368378.2016.1220389.

Halgamuge, M.N., Yak, S.K., Eberhardt, J.L., 2015. Reduced growth of soybean seedlings 
after exposure to weak microwave radiation from GSM 900 mobile phone and base station. Bioelectromagnetics 36, 87-95. https://doi.org/10.1002/BEM.21890.

Hautier, Y., Niklaus, P.A., Hector, A., 2009. Competition for light causes plant biodiversity loss after eutrophication. Science 324, 636-638.

Hayward, G.F., Phillipson, J., 1979. Community structure and functional role of small mammals in ecosystems. In: Stoddart, D.M. (Ed.), Ecology of Small Mammals. Springer, Netherlands, Dordrecht, pp. 135-211. https://doi.org/10.1007/978-94009-5772-5_4.

Heil, M., 2014. Herbivore-induced plant volatiles: targets, perception and unanswered questions. New Phytol. 204 (2), 297-306. https://doi.org/10.1111/nph.129.

Henderson, S.I., Bangay, M.J., 2006. Survey of RF exposure levels from mobile telephone base stations in Australia. Bioelectromagnetics 27, 73-76. https://doi.org/10.1002/ bem. 20174.

Hikosaka, K., Hirose, T., 1997. Leaf angle as a strategy for light competition: optimal and evolutionarily stable light-extinction coefficient within a leaf canopy. Écoscience 4, 501-507. https://doi.org/10.1080/11956860.1997.11682429.

Hintze, C., Heydel, F., Hoppe, C., Cunze, S., König, A., Tackenberg, O., 2013. D3: the dispersal and diaspore database - baseline data and statistics on seed dispersal. Perspect. Plant Ecol. Evol. System. 15, 180-192. https://doi.org/10.1016/j.ppees. 2013.02.001.

Howe, H.F., Zorn-Arnold, B., Sullivan, A., Brown, J.S., 2006. Massive and distinctive effects of meadow voles on grassland vegetation. Ecology 87, 3007-3013.

Jefferson, R.G., 1999. In: Lowland Grassland Management Handbook. English Nature/ The Wildlife Trusts, pp. 203-229.

Jinapang, P., Prakob, P., Wongwattananard, P., Islam, N.E., Kirawanich, P., 2010. Growth characteristics of mung beans and water convolvuluses exposed to $425-\mathrm{MHz}$ electromagnetic fields. Bioelectromagnetics 31, 519-527. https://doi.org/10.1002/bem. 20584.

Joseph, W., Verloock, L., Goeminne, F., Vermeeren, G., Martens, L., 2012. Assessment of RF exposures from emerging wireless communication technologies in different environments. Health Phys. 102, 161-172. https://doi.org/10.1097/HP. 0b013e31822f8e39.

Kattge, J., Díaz, S., Lavorel, S., et al., 2011. TRY - a global database of plant traits. Glob. Change Biol. 17, 2905-2935. https://doi.org/10.1111/j.1365-2486.2011.02451.x.

Kegge, W., Pierik, R., 2010. Biogenic volatile organic compounds and plant competition. Trends Plant Sci. 15, 126-132. https://doi.org/10.1016/j.tplants.2009.11.007.

Kim, B.C., Park, S.O., 2010. Evaluation of RF electromagnetic field exposure levels from cellular base stations in Korea. Bioelectromagnetics 31, 495-498. https://doi.org/10. 1002/bem. 20585.

Kleyer, M., Bekker, R.M., Knevel, I.C., et al., 2008. The LEDA Traitbase: a database of lifehistory traits of the Northwest European flora. J. Ecol. 96, 1266-1274. https://doi. org /10.1111/j.1365-2745.2008.01430.x.

Klotz, S., Kühn, I., Durka, W. (Eds.), 2002. BIOLFLOR - Eine Datenbank zu biologischökologischen Merkmalen der Gefäßpflanzen in Deutschland, Schriftenreihe für Vegetationskunde. Bundesamt für Naturschutz, Bonn.

Kundu, A., Gupta, B., 2014. Comparative SAR analysis of some Indian fruits as per the revised RF exposure guideline. IETE J. Res. 60 (4), 296-302. https://doi.org/10. 1080/03772063.2014.961981.

Kundu, A., Gupta, B., Mallick, A.I., 2016. SAR analysis in a typical bunch of grapes exposed to radio frequency radiation in Indian scenario. In: International Conference on Microelectronics, Computing and Communications (MicroCom), Durgapur, pp. 1-5. https://doi.org/10.1109/MicroCom.2016.7522559.

Laca, E.A., Lemaire, G., 2000. In: Field and Laboratory Methods for Grassland and Animal Production Research. CABI, Wallingford, pp. 103-121. https://doi.org/10.1079/ 9780851993515.0103.

Lázaro, A., Chroni, A., Tscheulin, T., Devalez, J., Matsoukas, C., Petanidou, T., 2016. Electromagnetic radiation of mobile telecommunication antennas affects the abundance and composition of wild pollinators. J. Insect Conserv. 20, 315-324. https:// doi.org/10.1007/s10841-016-9868-8.

Leuschner, C., Ellenberg, H., 2017. Ecology of Central European Non-Forest Vegetation: Coastal to Alpine, Natural to Man-Made Habitats: Vegetation Ecology of Central Europe. Springer International Publishing.

Lung, I., Soran, M.-L., Opriş, O., Truşcă, M.R.C., Niinemets, Ü., Copolovici, L., 2016. Induction of stress volatiles and changes in essential oil content and composition upon microwave exposure in the aromatic plant Ocimum basilicum. Sci. Total Environ. 569-570, 489-495. https://doi.org/10.1016/j.scitotenv.2016.06.147.

Majd, A., Amjad, L., Ghadirianmarnani, A., 2013. Ultrastructure, germination and viability in pollens of Achillea wilhelmsii C.Koch exposed to electromagnetic fields. Int. J. Sci. Technol. Res. 2 (2), 103-107.

Malkemper, E.P., Tscheulin, T., Vanbergen, A.J., Vian, A., Balian, E., Goudeseune, L., 2018. The impacts of artificial Electromagnetic Radiation on wildlife (flora and fauna). Current Knowledge Overview: A Background Document to the Web Conference. A report of the EKLIPSE project.

Mann, S.M., Cooper, T.G., Allen, S.G., Blackwell, R.P., Lowe, A.J., 2000. Exposure to radio waves near mobile phone base stations (No. NRPB-R321). National Radiological Protection Board.

Mestre, P., Serôdio, C., Morais, R., Azevedo, J., Melo-Pinto, P., 2010. Vegetation growth detection using wireless sensor networks. Proceedings of the World Congress on Engineering. Presented at the WCE 2010. June 30-July 2, 2010, London, UK.

Moorhead, L.C., Souza, L., Habeck, C.W., Lindroth, R.L., Classen, A.T., 2017. Small mammal activity alters plant community composition and microbial activity in an old-field ecosystem. Ecosphere 8, e01777. https://doi.org/10.1002/ecs2.1777.

Norman, J.M., Campbell, G.S., 1991. Canopy structure. In: Pearcy, R.W., Ehleringer, J.R., Mooney, H., Rundel, P.W. (Eds.), Plant Physiological Ecology. Field Methods and Instrumentation. Chapman and Hall, London and New York, pp. 301-325.

Odemer, R., Odemer, F., 2019. Effects of radiofrequency electromagnetic radiation (RF-
EMF) on honey bee queen deverlopment and mating success. Sci. Total Environ. 661, $553-562$.

Olasupo, T.O., Otero, C.E., Olasupo, K.O., Kostanic, I., 2016. Empirical path loss models for wireless sensor network deployments in short and tall natural grass environments. IEEE Trans. Antennas Propag. 64, 4012-4021. https://doi.org/10.1109/TAP.2016. 2583507.

Panagopoulos, D.J., Chavdoula, E.D., Margaritis, L.H., 2010. Bioeffects of mobile telephony radiation in relation to its intensity or distance from the antenna. Int. J. Radiat Biol. 86, 345-357. https://doi.org/10.3109/09553000903567961.

Panagopoulos, D.J., Johansson, O., Carlo, G.L., 2015a. Real versus simulated mobile phone exposures in experimental studies. Biomed. Res. Int. 2015, 1-8. https://doi. org/10.1155/2015/607053.

Panagopoulos, D.J., Johansson, O., Carlo, G.L., 2015b. Polarization: a key difference between man-made and natural electromagnetic fields, in regard to biological activity. Sci. Rep. 5, 14914. https://doi.org/10.1038/srep14914.

Panagopoulos, D.J., Margaritis, L.H., 2010. The effect of exposure duration on the biological activity of mobile telephony radiation. Mutat. Res. 699, 17-22. https://doi. org/10.1016/j.mrgentox.2010.04.010.

Pérez-Fontán, F., Mariño Espiñeira, P., 2008. Modelling the Wireless Propagation Channel: A Simulation Approach with MATLAB. Wiley-Blackwell, Chicester.

Pérez-Harguindeguy, N., Díaz, S., Garnier, E., Lavorel, S., Poorter, H., Jaureguiberry, P., Bret-Harte, M.S., Cornwell, W.K., Craine, J.M., Gurvich, D.E., et al., 2013. New handbook for standardised measurement of plant functional traits worldwide. Aust. J. Bot. 61, 167-234. https://doi.org/10.1071/BT12225.

Perring, M.P., Standish, R.J., Price, J.N., Craig, M.D., Erickson, T.E., Ruthrof, K.X., Whiteley, A.S., Valentine, L.E., Hobbs, R.J., 2015. Advances in restoration ecology: rising to the challenges of the coming decades. Ecosphere 6, 1-25. https://doi.org/ 10.1890/ES15-00121.1.

Pesnya, D.S., Romanovsky, A.V., 2013. Comparison of cytotoxic and genotoxic effects of plutonium-239 alpha particles and mobile phone GSM 900 radiation in the Allium cepa test. Mutat. Res./Genetic Toxicol. Environ. Mutagenesis 750, 27-33. https://doi. org/10.1016/j.mrgentox.2012.08.010.

Pickup, M., Westoby, M., Basden, A., 2005. Dry mass costs of deploying leaf area in relation to leaf size. Funct. Ecol. 19, 88-97. https://doi.org/10.1111/j.0269-8463. 2005.00927.x.

Pietruszewski, S., 2011. Electromagnetic fields, impact on seed germination and plant growth. In: Gliński, J., Horabik, J., Lipiec, J. (Eds.), Encyclopedia of Agrophysics. Springer Netherlands, Dordrecht, pp. 267-269. https://doi.org/10.1007/978-90481-3585-1_52.

Ponomaryova, I.A., Niño de Rivera y Oyarzabal, L., Ruíz Sánchez, E., 2009. Interaction of radio-frequency, high-strength electric fields with harmful insects. J. Microw. Power \& Electromagn. Energy 43, 17-27.

Reich, P.B., Wright, I.J., Cavender-Bares, J., Craine, J.M., Oleksyn, J., Westoby, M., Walters, M.B., 2003. The evolution of plant functional variation: traits, spectra, and strategies. Int. J. Plant Sci. 164, S143-S164. https://doi.org/10.1086/374368.

Roux, D., Vian, A., Girard, S., Bonnet, P., Paladian, F., Davies, E., Ledoigt, G., 2006. Electromagnetic fields ( $900 \mathrm{MHz}$ ) evoke consistent molecular responses in tomato plants. Physiol. Plant. 128, 283-288. https://doi.org/10.1111/j.1399-3054.2006. 00740.x.

Schwartz, J.L., Philogene, B.J.R., Stewart, J.G., Mealing, G.A., Duval, F.M., 1985. Chronic exposure of the tobacco hornworm to pulsed microwaves- effects on development. J Microw Power 20, 85-93. https://doi.org/10.1080/16070658.1985.11720295.

Scialabba, A., Tamburello, C., 2002. Microwave effects on germination and growth of radish (Raphanus sativus L.) seedlings. Acta Botanica Gallica 149, 113-123. https:// doi.org/10.1080/12538078.2002.10515947.

Senavirathna, M.D., Asaeda, T., 2014. The significance of microwaves in the environment and its effect on plants. Environ. Rev. 22, 220-228. https://doi.org/10.1139/er 2013-0061.

Sharma, V.P., Singh, H.P., Kohli, R.K., Batish, D.R., 2009. Mobile phone radiation inhibits Vigna radiata (mung bean) root growth by inducing oxidative stress. Sci. Total Environ. 407, 5543-5547. https://doi.org/10.1016/j.scitotenv.2009.07.006.

Sharma, V.P., Kumar, N.R., 2010. Changes in honeybee behaviour and biology under the influence of cellphone radiations. Curr. Sci. 98, 1376-1378.

Singh, H.P., Sharma, V.P., Batish, D.R., Kohli, R.K., 2012. Cell phone electromagnetic field radiations affect rhizogenesis through impairment of biochemical processes. Environ. Monit. Assess. 184, 1813-1821. https://doi.org/10.1007/s10661-0112080-0.

Smith, E.P., 2006. BACI design. In: Encyclopedia of Environmetrics. John Wiley \& Sons, Ltd, pp. 141-148. https://doi.org/10.1002/9780470057339.vab001.pub2.

Soran, M.-L., Stan, M., Niinemets, Ü., Copolovici, L., 2014. Influence of microwave frequency electromagnetic radiation on terpene emission and content in aromatic plants. J. Plant Physiol. 171, 1436-1443. https://doi.org/10.1016/j.jplph.2014.06. 013.

Stefi, A.L., Margaritis, L.H., Christodoulakis, N.S., 2016. The effect of the non ionizing radiation on cultivated plants of Arabidopsis thaliana (Col.). Flora 223, 114-120. https://doi.org/10.1016/j.flora.2016.05.008.

Stefi, A.L., Margaritis, L.H., Christodoulakis, N.S., 2017a. The effect of the non ionizing radiation on exposed, laboratory cultivated upland cotton (Gossypium hirsutum L.) plants. Flora 226, 55-64. https://doi.org/10.1016/j.flora.2016.11.009.

Stefi, A.L., Margaritis, L.H., Christodoulakis, N.S., 2017b. The effect of the non-ionizing radiation on exposed, laboratory cultivated maize (Zea mays L.) plants. Flora 233, 22-30. https://doi.org/10.1016/j.flora.2017.05.008.

Stefi, A.L., Margaritis, L.H., Christodoulakis, N.S., 2017c. The aftermath of long-term exposure to non-ionizing radiation on laboratory cultivated pine plants (Pinus halepensis M.). Flora 234, 173-186. https://doi.org/10.1016/j.flora.2017.07.016.

Stewart, K.E.J., Bourn, N.a.D., Thomas, J.A., 2001. An evaluation of three quick methods 
commonly used to assess sward height in ecology. J. Appl. Ecol. 38, 1148-1154. https://doi.org/10.1046/j.1365-2664.2001.00658.x.

Stohlgren, T.J., 2006. Measuring Plant Diversity: Lessons from the Field, 1st ed. Oxford University Press, Oxford, New York.

Tanner, J.A., Romero-Sierra, C., 1974. Beneficial and harmful accelerated growth induced by the action of nonionizing radiation. Ann. N. Y. Acad. Sci. 238, 171-175. https:// doi.org/10.1111/j.1749-6632.1974.tb26786.x.

Trabelsi, S., Nelson, S.O., 2003. Free-space measurement of dielectric properties of cereal grain and oilseed at microwave frequencies. Meas. Sci. Technol. 14, 589. https://doi. org/10.1088/0957-0233/14/5/308.

Urbinello, D., Joseph, W., Huss, A., Verloock, L., Beekhuizen, J., Vermeulen, R., Martens, L., Röösli, M., 2014. Radio-frequency electromagnetic field (RF-EMF) exposure levels in different European outdoor urban environments in comparison with regulatory limits. Environ. Int. 68, 49-54. https://doi.org/10.1016/j.envint.2014.03.007.

van der Pijl, L., 1982. Principles of Dispersal in Higher Plants, 3rd ed. Springer-Verlag, Berlin-Heidelberg-New York.

Vian, A., Davies, E., Gendraud, M., Bonnet, P., 2016. Plant responses to high frequency electromagnetic fields. Biomed Res. Int. 2016, 1830262. https://doi.org/10.1155/ 2016/1830262.

Vian, A., Faure, C., Girard, S., Davies, E., Hallé, F., Bonnet, P., Ledoigt, G., Paladian, F., 2007. Plants respond to GSM-like radiation. Plant Signal. Behav. 2, 522-526. https:// doi.org/10.4161/psb.2.6.4657.

Violle, C., Navas, M.-L., Vile, D., Kazakou, E., Fortunel, C., Hummel, I., Garnier, E., 2007. Let the concept of trait be functional!. Oikos 116, 882-892. https://doi.org/10.1111/ j.0030-1299.2007.15559.x.
Vojtech, E., Turnbull, L.A., Hector, A., 2007. Differences in light interception in grass monocultures predict short-term competitive outcomes under productive conditions. PLoS One 2, e499.

Wainwright, C.E., Staples, T.L., Charles, L.S., Flanagan, T.C., Lai, H.R., Loy, X., Reynolds, V.A., Mayfield, M.M., 2018. Links between community ecology theory and ecological restoration are on the rise. J. Appl. Ecol. 55, 570-581. https://doi.org/10.1111/ 1365-2664.12975.

Waldmann-Selsam, C., Balmori-de la Puente, A., Breunig, H., Balmori, A., 2016. Radiofrequency radiation injures trees around mobile phone base stations. Sci. Total Environ. 572, 554-569. https://doi.org/10.1016/j.scitotenv.2016.08.045.

Weitzen, J.A., Wallace, M.S., 2002. Comparision of polarization and space diversity in operational cellular and PCS systems. In: Ganesh, R., Pahlavan, K. (Eds.), Wireless Network Deployments. Kluwer Academic Publishers, New York-Boston-DordrechtLondon-Moscow, pp. 23-37.

Westoby, M., 1998. A leaf-height-seed (LHS) plant ecology strategy scheme. Plant Soil 199, 213-227. https://doi.org/10.1023/A:1004327224729.

Westoby, M., Falster, D.S., Moles, A.T., Vesk, P.A., Wright, I.J., 2002. Plant ecological strategies: some leading dimensions of variation between species. Annu. Rev. Ecol. Syst. 33, 125-159. https://doi.org/10.1146/annurev.ecolsys.33.010802.150452.

Wright, I.J., Reich, P.B., Westoby, M., et al., 2004. The worldwide leaf economics spectrum. Nature 428, 821-827. https://doi.org/10.1038/nature02403.

Zehm, A., Nobis, M., Schwabe, A., 2003. Multiparameter analysis of vertical vegetation structure based on digital image processing. Flora - Morphol. Distrib. Funct. Ecol. Plants 198, 142-160. https://doi.org/10.1078/0367-2530-00086. 